\title{
Vertical Distribution of Heterodera schachtii under Susceptible, Resistant, or Tolerant Sugar Beet Cultivars
}

Andreas Westphal, Julius-Kühn-Institut, Institute for Plant Protection in Field Crops and Grassland, Messeweg 11/12, D-38104 Braunschweig, Germany

\begin{abstract}
Westphal, A. 2013. Vertical distribution of Heterodera schachtii under susceptible, resistant, or tolerant sugar beet cultivars. Plant Dis. 97:101-106.

Heterodera schachtii is managed by rotation with non-hosts, resistant cover crops, and resistant and tolerant sugar beet cultivars. Microplots $60 \mathrm{~cm}$ deep and $30 \mathrm{~cm}$ in diameter containing steamed field soil were (i) noninfested or infested with $550 \mathrm{H}$. schachtii eggs per $100 \mathrm{~g}$ at (ii) 0 to $60 \mathrm{~cm}$, (iii) 0 to $30 \mathrm{~cm}$ or (iv) 30 to $60 \mathrm{~cm}$ in depth. Plots were planted to susceptible, resistant, and tolerant sugar beets. Five weeks later, the sugar beet canopy was largest in condition i, smallest in condition ii, and intermediate in conditions iii and iv. White sugar yield (WSY) was highest in condition i, second in condition iv, lowest in condition ii, and intermediate in condition iii. Cultivar-specific final

experiments utilizing $1-\mathrm{m}^{2}$ microplots, naturally occurring $H$. schachtii populations were suppressed with fosthiazate at depth layers in reverse to those infested in the first experiment, and planted to susceptible, resistant, and tolerant sugar beets. In one experiment, WSY was highest in soil treated with fosthiazate at 0 to $60 \mathrm{~cm}$ in depth, lowest in nontreated, unaffected in soil treated at 30 to $60 \mathrm{~cm}$ in depth, and somewhat lower in soil treated at 0 to $30 \mathrm{~cm}$ in depth. In all cultivars, early root penetration predicted canopy diameter; only in the susceptible cultivar did the canopy diameter predict WSY. Deep-occurring $H$. schachtii can impact productivity in sugar beet cropping.
\end{abstract} nematode numbers were independent of the level of infestation. In two
For one and a half centuries, Heterodera schachtii has been recognized as a severe problem of sugar beet production (5). It occurs in the major sugar beet production regions in Europe and other areas of the world $(3,13)$, and is known to cause yield losses of other host crops. For example, cruciferous vegetables are susceptible hosts and require proper management strategies when climate conditions favor the potential for nematode damage (7). The increasing cropping intensity of plants that are hosts to $H$. schachtii, specifically the increases in acreages of canola in European sugar beet rotations, has rekindled the interest in the extent of nematode infestations in given fields. The hypothesis that the development of deep-occurring populations may be favored in the cropping system with various host plants of $H$. schachtii that are known for deep-rooting growth patterns was the basis for the current project. Limited information exists pertaining to the impact of deep-occurring populations on the overall pathogenic success of $H$. schachtii, especially on the recently released sugar beet cultivars with resistant or tolerant host status to this nematode. These distinct plant characteristics of resistance and tolerance refer to either suppression of nematode reproduction or reduced sensitivity to damage in response to infection of $H$. schachtii, respectively (12).

Published experiments with plant-parasitic nematodes in row crops defined the damage potential of deep-occurring populations of the reniform nematode in cotton and soybean $(16,17,22)$. With Rotylenchulus reniformis, the high damage potential of the nematode at depths below $60 \mathrm{~cm}$ was demonstrated by selective fumigation treatments with 1,3-D-containing compounds $(17,22)$. In those studies, only limited vertical movement of the nematode between soil layers was detected once population suppression by the nematicide was achieved at the predetermined depths. However, more importantly, nematodes that had access to the cotton root

Corresponding author: A. Westphal,

E-mail: andreas.westphal@jki.bund.de

Accepted for publication 10 August 2012.

http://dx.doi.org/10.1094/PDIS-05-12-0476-RE

(C) 2013 The American Phytopathological Society system also caused measurable plant damage, presumably regardless of the soil layer where they were located.

The objective of this study was to determine whether deepoccurring populations of $H$. schachtii could damage sugar beet cultivars that express different responses to the nematode parasite, and whether a susceptible, resistant, or tolerant cultivar affected population development differentially at various vertical layers.

\section{Materials and Methods}

Two types of experiments were conducted. In one experiment, infestations with $H$. schachtii were established at 0 to $30 \mathrm{~cm}$ or 30 to $60 \mathrm{~cm}$ by adding nematode populations into steamed sandy soil at these depths, or in the second type of experiments, by suppressing population densities at the corresponding depths by application of the nematicide fosthiazate (Nemathorin 10G; Syngenta Crop). In both types of experiments, depending on the experiment, three or six seeds of 'Beretta' (susceptible to $H$. schachtii), 'Sanetta' (resistant to $H$. schachtii) or 'Pauletta' (tolerant to $H$. schachtii) were planted at each planting site. Three weeks after seeding at the cotyledon stage with initial true leaves (Biologische Bundesanstalt, Bundessortenamt und Chemische Industrie, BBCH 10) (9), seedlings were removed to maintain one seedling per planting site in the plots. The spare seedlings were collected from each plot, and root penetration by second-stage juveniles (J2) after staining the roots with acid fuchsin (2) was measured. From each replication, at least two seedlings per cultivar in each treatment were recovered for staining. The remaining plants were maintained at standard production conditions typical for this region of Germany. Plant growth was monitored and the perpendicular diameter of the plant canopy was measured 5 weeks after seeding, when most noninfested plants had reached four true leaves (BBCH 14). At harvest, fresh weights of the washed taproots were determined. Sugar content and the sugar extractionimpacting contents were determined by the Jülich sugar beet processing plant experimental laboratory. Harvest data were reported as white sugar yields (WSYs) per plant.

Experiment with infestation at distinct depth layers. On 23 April, steamed sandy soil $(88.4 \%$ sand, $8.4 \%$ silt, $2.2 \%$ clay, $\mathrm{pH}$ 4.9 , and $1.9 \%$ organic matter [O.M.]) was placed in $30-\mathrm{cm}$ diameter PVC tubes $65 \mathrm{~cm}$ long inserted perpendicularly to a depth of 60 $\mathrm{cm}$ plus $5 \mathrm{~cm}$ of a watering rim into a field at $1.80-\mathrm{m}$ center-to- 
center spacing. Soils were infested with cysts of $H$. schachtii Schach0 (= wild type devoid of virulence on any resistant sources) per definition by Müller (11) from greenhouse canola cultures in loess soil, establishing the equivalent of 550 eggs per $100 \mathrm{~g}$ of soil before placing into the tubes, or left noninfested (only loess added). Four treatments were prepared: (i) noninfested; (ii) infested throughout the soil column $(0$ to $60 \mathrm{~cm})$; (iii) infested at the shallow soil depth (0 to $30 \mathrm{~cm}$ ), noninfested at greater depth; and (iv) infested at depth of 30 to $60 \mathrm{~cm}$ only. Each treatment was replicated five times in a randomized complete block design. On 24 April, plots were planted with six seeds of one of the sugar beet cultivars (Beretta, Sanetta, or Pauletta) in the horizontal center of each of the plots.

Experiments with suppression with fosthiazate at discrete depths. Microplots of $1 \mathrm{~m}^{2}$ surface area encased with concrete walls in excess of $60 \mathrm{~cm}$ in depth containing sandy soils $(88.2 \%$ sand, $7.4 \%$ silt, $4.4 \%$ clay, $\mathrm{pH} 6.9,2.4 \%$ O.M.) were used for two nematode-suppression experiments with fosthiazate. These plots had been infested with $H$. schachtii pathotype Schach0 (16 plots) or Schach1 (16 plots) per definition by Müller more than 15 years before initiation of the current experiment, and used for various $H$. schachtii-related studies (J. Müller, personal communication). $H$. schachtii Schach0 is the wild type with no virulence on any resistance sources; Schach1 is virulent on sugar beet genotypes that carry the Hs $1^{\text {Pro-1 }}$ gene for resistance to $H$. schachtii (11). For each of the pathotypes, population densities in the fall prior to this experiment were used for grouping plots into four blocks of similar initial nematode population density. Plots were sampled prior to treatment with a 2-cm-diameter soil probe to a depth of $60 \mathrm{~cm} ; 12$ soil cores per plot were separated into 0 - to $30-\mathrm{cm}$ and $30-$ to $60-\mathrm{cm}$ depth composite samples. In both experiments, the following treatments were assigned at random to plots of each of the four blocks: (i) fosthiazate application at 0 to $60 \mathrm{~cm}$, (ii) nontreated, (iii) fosthiazate applied at depth of 30 to $60 \mathrm{~cm}$, and (iv) fosthiazate applied at depth of 0 to $30 \mathrm{~cm}$. For the treatments, soils of the 0 - to $30-\mathrm{cm}$ depth were removed from the plots. Soil of the deep layer $(30$ to $60 \mathrm{~cm}$ ) of each plot was mixed with a spade and a digging fork. In the appropriate treatments, fosthiazate at $7.5 \mathrm{~g} / \mathrm{m}^{2}$ per 30 $\mathrm{cm}$ depth layer was spread on the surface of the respective layer surface and incorporated into the soil with the spade and fork by vertical and horizontal mixing. This rate was chosen to provide maximum nematode suppression potential in the absence of phyto-

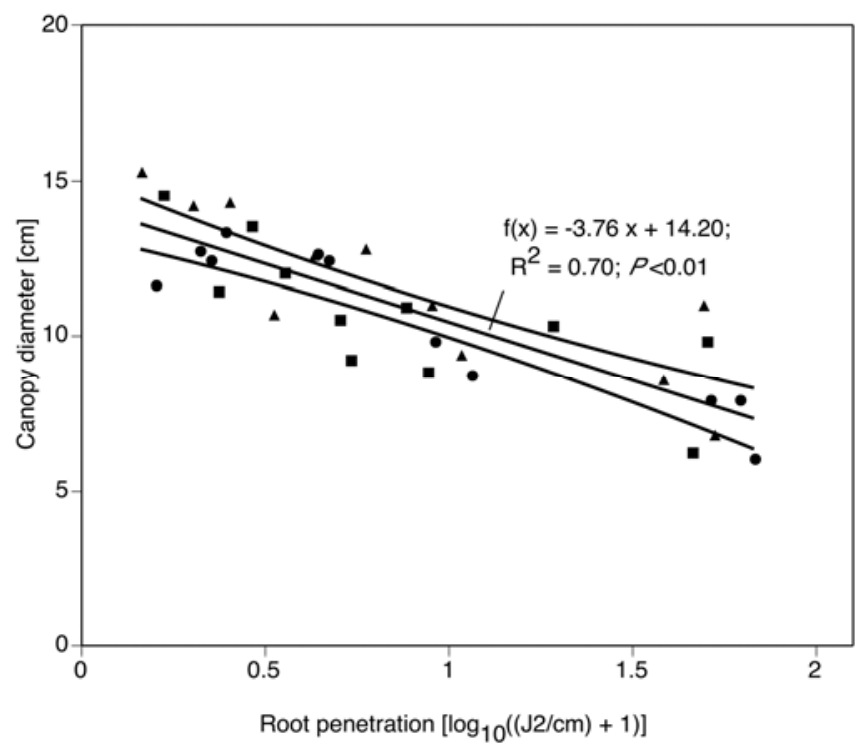

Fig. 1. Plant canopy of sugar beet: 'Beretta' (susceptible, - $\mathbf{m})$,'Sanetta' (resistant, $\bullet$ ), or 'Pauletta' (tolerant, $\mathbf{\Delta}$ ) in relation to root penetration by Heterodera schachtii 3 weeks after seeding. The mutual regression line with $95 \%$ confidence intervals is shown. Noninoculated controls of the first field experiment were omitted from this analysis. toxicity, the latter determined in a preliminary test. Soils were compacted lightly to ensure soil structure supportive of plant growth. The top layer was replaced into its original plot and treated with fosthiazate at the $7.5 \mathrm{~g} / \mathrm{m}^{2}$ rate if appropriate by the treatment plan. Mechanical manipulations were similar for all plots, including those not receiving fosthiazate. Beretta, Sanetta, or Pauletta sugar beet were planted into three randomly assigned 1-m rows within each of the plots at three planting spots with three seeds each. This experimental set-up resulted in two experiments with a split-plot design, one with Schach0 with four replications, and one for Schach1 with four replications.

To determine the infectivity of $\mathbf{J} 2$ of $H$. schachtii after soil treatment with fosthiazate, composite soil samples of four cores per plot were collected on 12 May and 17 June and subjected to a modified radish bioassay (21). Briefly, the equivalents of $100 \mathrm{~g}$ of soil dry weight were placed in 11-cm-diameter plastic food containers. Uniform moisture (approximately 50\% waterholding field capacity) was achieved by adding the required amount of water. Soils within each container were planted with one seed of radish (Raphanus sativus 'Saxa 3') and the units were covered with a lid. After 4 days of incubation with day and night at 16 and $8 \mathrm{~h}$ and 28 and $23^{\circ} \mathrm{C}$, respectively, seedlings were washed free of soil and processed for detection of $\mathbf{J} 2$ via staining with acid fuchsin (2). The root lengths of radish seedlings were measured with a ruler and penetration by $\mathrm{J} 2$ reported as $\mathrm{J} 2$ per centimeter of root.

Nematode population densities at harvest. At harvest of all three experiments, $H$. schachtii soil population densities were determined from soil samples collected with a 2-cm-diameter soil probe from the immediate vicinity of the plants of each cultivar and soil infestation combination. In the infestation experiment, 12 cores per plant were taken, composited per 0- to 30- and 30- to 60$\mathrm{cm}$ depth layer. In the suppression experiments, four cores were taken per each of the three plants of one subplot and composited per depth. Samples of $400 \mathrm{~g}$ fresh weight were used for the extraction by density centrifugation (10). To account for differences in soil moisture in the $1-\mathrm{m}^{2}$ plots, moisture content was determined gravimetrically. Final population densities were reported per $100 \mathrm{~g}$ of soil dry weight. In addition, nematodes per soil fresh weight, or per $100 \mathrm{~cm}^{3}$ of soil, were also calculated and analyzed.

Statistical analysis. Data were entered into the proper analysis of variance (ANOVA) in Proc GLM in SAS (SAS Institute, Cary, $\mathrm{NC}$ ) after testing for homogeneity of the error variances and conducting the appropriate transformations (log-transformed for nematode counts: $\log _{10}[x+1]$; square root-transformed for plant yield data: $\sqrt{ } \mathrm{x}$ ) where necessary. Pooling of error terms was done where appropriate to simplify models. Mean separation was conducted in Proc MIXED (SAS Institute). Data from the infestation experiment that did not include the depth factor were analyzed as a randomized complete block design. In the experiments of suppression with fosthiazate at discrete depths, data were analyzed as a randomized complete block design because the split-plot error term could be pooled. If error variances of both experiments were homogenous, a combined analysis was conducted. In the infestation experiment, nematode data were analyzed as split-plot design because the split-block error term of the original statistical design was pooled. In the chemical suppression experiments, nematode numbers were analyzed as split-plot splitblock design. In addition, nematode data from the suppression experiments were analyzed relating nematode numbers per soil weight with intrinsic soil moisture, related to soil dry weight or to soil volume. This was done to determine whether different soil tilth and moisture content at various soil depths led to confounding errors and misinterpretations of the results. The relationships of early root penetration on canopy growth and the predictive potential of the canopy diameter on final WSY were first compared for each of the three cultivars across the experiments (Proc GLM; SAS Institute). If slopes were not significantly different, a combined linear regression was computed in Proc REG (SAS Institute). In a second step, the slopes of the regression lines of the different cultivars were compared in this way. Again, if the slopes 
were similar, data were combined. Noninfested controls were eliminated from this analysis because these had outlier parameters.

\section{Results}

Experiment with infestation at distinct depth layers. Three weeks after planting (BBCH 10), penetration rates in the susceptible, resistant, and tolerant cultivars were similar $(57 \pm 5,53 \pm 5$, or $46 \pm 6 / \mathrm{cm}$ of root; data not shown). All treatments that had received the nematode infestation had similarly higher penetration rates than those without infestation (virtually no nematodes) independent of infestation depth $(P<0.01$; data not shown). After 5 weeks (BBCH 14), canopy diameter was largest for the noninfested treatments $(20.1 \pm 0.6 \mathrm{~cm})$ and lowest in the treatment with infestation at both depth layers $(6.3 \pm 0.5 \mathrm{~cm})$; treatments with infestations at only one depth were intermediate $(P<0.01$; data not shown). Averaged per cultivar, Sanetta $(10.1 \pm 1.2 \mathrm{~cm})$ was slightly smaller than the similar Beretta $(11.8 \pm 1.3 \mathrm{~cm})$ and Pauletta $(11.8 \pm 1.3 \mathrm{~cm} ; P=0.02$; data not shown $)$. Overall, cultivars responded similarly to nematode infestation (Fig. 1).

At harvest, cultivars had similar responses to nematode infestation (Table 1). The taproot yields were highest for the noninfested control $(-,-)$, and lowest for the treatment infested at the entire depth $(+,+)$; the treatments infested at only one depth were intermediate $(P<0.01$; Table 1$)$. Pauletta had higher average yields than the similar Beretta and Sanetta $(P<0.01$; Table 1). Similar observations were made for the WSY, except that infestation at the 0 - to $30-\mathrm{cm}$ depth was not distinguishable from plots infested over the entire depth or plots infested at the 30 - to 60-cm depth $(P=$ 0.0152; Table 1).

Experiments with suppression with fosthiazate at discrete depth. Initial population densities of $H$. schachtii were $557 \pm 113$ eggs per $100 \mathrm{~g}$ of soil (log: 2.12) for Schach0 and 2,829 \pm 444 eggs per $100 \mathrm{~g}$ of soil (log: 3.23) for Schach1 (data not shown). On 12 May, no J2 were detected by the radish root bioassay plots that had been chemically treated at both depths (-,-) and the treated 30- to 60 -cm-depth soil (Table 2). In the cores that had not received chemical treatment $(+,+)$, more $\mathrm{J} 2$ were detected in the 0 - to $30-\mathrm{cm}$ depth than the 30 - to $60-\mathrm{cm}$ depth; when soil at 0 to $30 \mathrm{~cm}$ was treated, J2 numbers were indistinguishable from the nontreated 30to 60-cm-depth layers (Table 2). On 17 June, more J2 were detected in the $0-$ to $30-\mathrm{cm}$ layer than at 30 to $60 \mathrm{~cm}$ in cores that had not received chemical treatment and those that had been treated at 30 to $60 \mathrm{~cm}$ (Table 2). Numbers of J2 remained low under Schach0 when both depths had been treated but higher numbers, indistinguishable from plots without chemical treatment, were detected in Schach1 plots of this treatment (Table 2). Penetration was more numerous in Schach1 than in Schach0 at the June sampling time whereas this was only a trend at the May sampling (Table 2).

Root penetration of plants of the different sugar beet cultivars raised in the $1-\mathrm{m}^{2}$ microplots was similar for both pathotypes. In plots with pathotype Schach0, the lowest population densities $(0.9$ $\pm 0.4 / \mathrm{cm}$ of root) were detected in the treatment with no nematodes expected, whereas those with the entire column devoid of chemical treatment had the highest populations $(5.0 \pm 1.5 / \mathrm{cm}$ of root $)$. Plots with only the 0 - to $30-\mathrm{cm}$ depth not chemically treated had numbers of $\mathbf{J} 2$ detected $(2.2 \pm 0.6 / \mathrm{cm}$ of root $)$ similar to those at 30 - to $60-\mathrm{cm}$ depth not chemically treated $(2.3 \pm 0.8 / \mathrm{cm}$ of root; data not shown). In Schach1, a similar pattern was observed, with the least $\mathrm{J} 2$ in the whole depth-treated $(2.8 \pm 2.9 / \mathrm{cm}$ of root $)$, high in the untreated $(13.0 \pm 2.9 / \mathrm{cm}$ of root), similar in the 30 - to $60-\mathrm{cm}$ depth with nematode treatment $(14.0 \pm 5.1 / \mathrm{cm}$ of root $)$, and somewhat reduced in the deep nematode-containing treatment $(5.9 \pm 1.4 / \mathrm{cm}$

Table 1. Taproot weights and white sugar yields of 'Beretta', 'Sanetta', and 'Pauletta' grown in soil columns of $30 \mathrm{~cm}$ in diameter infested at various depth layers with Heterodera schachtii ${ }^{\mathrm{y}}$

\begin{tabular}{|c|c|c|c|c|c|c|c|c|c|}
\hline \multicolumn{2}{|c|}{ Nematodes $(\mathbf{c m})^{\mathrm{z}}$} & \multicolumn{4}{|c|}{ Taproot weight (kg) } & \multicolumn{4}{|c|}{ White sugar yield (g) } \\
\hline $0-30$ & $30-60$ & Beretta & Sanetta & Pauletta & Mean & Beretta & Sanetta & Pauletta & Mean \\
\hline - & - & $1.52 \pm 0.24$ & $1.27 \pm 0.15$ & $1.52 \pm 0.31$ & $1.44 \pm 0.13 \mathrm{a}$ & $243 \pm 38$ & $205 \pm 24$ & $226 \pm 46$ & $225 \pm 20 a$ \\
\hline+ & + & $0.33 \pm 0.07$ & $0.51 \pm 0.14$ & $0.80 \pm 0.07$ & $0.55 \pm 0.07 \mathrm{c}$ & $53 \pm 12$ & $85 \pm 23$ & $128 \pm 12$ & $89 \pm 12 c$ \\
\hline+ & - & $0.74 \pm 0.06$ & $0.55 \pm 0.06$ & $0.82 \pm 0.07$ & $0.71 \pm 0.05 b$ & $110 \pm 9$ & $88 \pm 10$ & $130 \pm 11$ & $110 \pm 7 b c$ \\
\hline- & + & $0.86 \pm 0.14$ & $0.58 \pm 0.04$ & $0.97 \pm 0.10$ & $0.80 \pm 0.07 \mathrm{~b}$ & $132 \pm 22$ & $103 \pm 8$ & $154 \pm 16$ & $124 \pm 10 b$ \\
\hline Mean \pm SE & $\ldots$ & $0.86 \pm 0.12 \mathrm{y}$ & $0.73 \pm 0.08 \mathrm{y}$ & $1.03 \pm 0.10 \mathrm{z}$ & $0.87 \pm 0.06$ & $135 \pm 19 y$ & $120 \pm 8 y$ & $160 \pm 15 \mathrm{z}$ & $138 \pm 9$ \\
\hline$P_{\text {Treatment (T) }}$ & $\ldots$ & $\ldots$ & 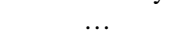 & $\ldots$ & $<0.01$ & $\ldots$ & & $\ldots$ & 0.0152 \\
\hline$P_{\text {Cultivar (C) }}$ & $\ldots$ & $\ldots$ & $<0.01$ & $\ldots$ & $\ldots$ & $\ldots$ & $<0.01$ & $\ldots$ & $\ldots$ \\
\hline$P_{(\mathrm{T} \times \mathrm{C})}$ & $\ldots$ & $\ldots$ & 0.2178 & $\ldots$ & $\ldots$ & $\ldots$ & 0.1992 & $\ldots$ & $\ldots$ \\
\hline
\end{tabular}

${ }^{y}$ Numbers within one column or one row of the same parameter followed by the same letter were not significantly different when tested by least significant difference mean separation at $P=0.05$. Original means are presented, mean separation was done of the square root-transformed data $(\sqrt{ } x)$ at $P=0.05$.

${ }^{z}$ During soil preparation, loess carrier was added (+) with $H$. schachtii establishing 500 eggs per $100 \mathrm{~g}$ of soil, or $(-)$ without. $\mathrm{SE}=$ standard error.

Table 2. Penetration of radish seedling roots (second-stage juveniles per centimeter of root) of 'Saxa' in a bioassay of $100 \mathrm{~g}$ dry weight of soil collected from 0 - to 30- or 30- to 60-cm depths at two sample dates 3 (12 May 2009) or 8 (17 June 2009) weeks after application of fosthiazate at $7.5 \mathrm{~g} / \mathrm{m}^{2}$ in microplots infested with Heterodera schachtii ${ }^{\mathrm{y}}$

\begin{tabular}{|c|c|c|c|c|c|c|}
\hline \multicolumn{2}{|c|}{ Nematodes $(\mathbf{c m})^{\mathrm{z}}$} & \multirow[b]{2}{*}{ Depth (cm) } & \multicolumn{2}{|c|}{12 May 2009} & \multicolumn{2}{|c|}{17 June 2009} \\
\hline 0-30 & $30-60$ & & Schach0 & Schach1 & Schach0 & Schach1 \\
\hline- & - & $0-30$ & $0.00 \pm 0.00$ & $0.00 \pm 0.00$ & $0.08 \pm 0.06 \mathrm{bc}$ & $1.92 \pm 0.72 \mathrm{abc}$ \\
\hline - & - & $30-60$ & $0.00 \pm 0.00$ & $0.00 \pm 0.00$ & $0.04 \pm 0.03 \mathrm{bc}$ & $0.04 \pm 0.03 \mathrm{~d}$ \\
\hline+ & + & $0-30$ & $1.42 \pm 0.82 \mathrm{a}$ & $4.19 \pm 1.00 \mathrm{a}$ & $1.73 \pm 0.83 \mathrm{a}$ & $3.87 \pm 0.87 \mathrm{ab}$ \\
\hline+ & + & $30-60$ & $0.37 \pm 0.24 \mathrm{~b}$ & $1.14 \pm 0.44 \mathrm{~b}$ & $0.19 \pm 0.13 b c$ & $0.84 \pm 0.28 \mathrm{~cd}$ \\
\hline+ & - & $0-30$ & $0.84 \pm 0.37 \mathrm{ab}$ & $2.68 \pm 0.69 \mathrm{a}$ & $1.41 \pm 0.41 \mathrm{a}$ & $4.34 \pm 1.56 \mathrm{a}$ \\
\hline+ & - & $30-60$ & $0.00 \pm 0.00$ & $0.00 \pm 0.00$ & $0.03 \pm 0.03 \mathrm{c}$ & $0.12 \pm 0.05 \mathrm{~d}$ \\
\hline- & + & $0-30$ & $0.23 \pm 0.19 b$ & $0.28 \pm 0.28 b$ & $0.60 \pm 0.36 \mathrm{~b}$ & $2.20 \pm 1.49 \mathrm{bc}$ \\
\hline - & + & $30-60$ & $0.33 \pm 0.18 b$ & $0.54 \pm 0.30 \mathrm{~b}$ & $0.13 \pm 0.07 b c$ & $2.12 \pm 1.13 \mathrm{abc}$ \\
\hline Mean \pm SE & $\ldots$ & $\ldots$ & $0.40 \pm 0.14$ & $1.10 \pm 0.30$ & $0.52 \pm 0.16 \mathrm{y}$ & $1.93 \pm 0.40 \mathrm{x}$ \\
\hline$P_{\text {Treatment (T) }}$ & $\ldots$ & $\ldots$ & 0.3203 & $<0.01$ & $<0.01$ & 0.2473 \\
\hline$P_{\text {Depth (D) }}$ & $\ldots$ & $\ldots$ & 0.0998 & 0.0120 & $<0.01$ & $<0.01$ \\
\hline$P_{(\mathrm{T} \times \mathrm{D})}$ & $\ldots$ & $\ldots$ & 0.0301 & $<0.01$ & 0.0145 & 0.0108 \\
\hline
\end{tabular}

y Numbers are untransformed means \pm standard error (SE) of the means; data within one column or one row of the same parameter followed by the same letter were not significantly different when $\log$-transformed data $\left(\log _{10}[x+1]\right)$ were tested at $P=0.05$. Values with zero error variances were excluded from analysis of variance; means of the experiments within each sampling time followed by the same letter were not significantly different at $P=0.05$.

${ }^{\mathrm{z}}$ Nematodes were expected at depths indicated $(+)$ and not expected at layers treated with fosthiazate at $7.5 \mathrm{~g} / \mathrm{m}^{2}$ per $30-\mathrm{cm}$ soil layer $(-)$. 
of root; data not shown). An opposite outcome was observed for plant canopy measurements where, in general, plants with limited nematode penetration had larger diameters than those with more J2 in the roots (Fig. 1). This interrelationship was best described with a linear regression when combined with the data of the first experiment (Fig. 1). At harvest of Schach0, no effects of the nematicide treatment on taproot or WSY were observed; yields were overall higher in Beretta and Pauletta than in Sanetta (Table 3). In Schach1, the chemically treated plots had the highest yield, similar to those with nematodes only in the shallow layer; plots with nematodes in both layers or those with nematodes only in deep layers had the lowest yields, the latter indistinguishable from the nematode treatments at 0 to 30 and 0 to $60 \mathrm{~cm}$ (Table 3). Cultivar differences were more pronounced. As expected, Pauletta had the highest, Beretta the second, and Sanetta the lowest yields (Table 3). The early canopy diameter predicted WSY in the susceptible Beretta but the quantitative response was not significant in the resistant Sanetta, and differed in the experimental contexts in the tolerant Pauletta (Fig. 2).

Nematode population densities at harvest. In the infestation experiment, egg population densities were higher overall at the 0to $30-\mathrm{cm}$ depth $(14,241$ per $100 \mathrm{~g}$ of soil; log: 2.91) than at the 30to 60 -cm depth $(11,262$ per $100 \mathrm{~g}$ of soil; log: 2.69) $(P=0.0442$; data not shown). Egg population densities followed a similar pattern under the three cultivars but the overall population densities were highest under Beretta (32,699 per $100 \mathrm{~g}$ of soil; $\log 3.66)$, second under Pauletta (5,343 per $100 \mathrm{~g}$ of soil; $\log : 2.89)$, and lowest under Sanetta (212 per $100 \mathrm{~g}$ of soil; log: 1.86) $(P<0.01$; data not shown). In each infestation treatment, Beretta had the highest, Pauletta the second highest, and Sanetta the lowest population densities $(P<0.01$; Fig. 3$)$.

In the suppression experiments when analyzing the nematode population densities per weight of moist soil, per weight of dry soil, or per volume of moist soil, no differences in probabilities were detected for Schach0 or Schach1 (Table 4; data not shown). Data were analyzed on a per-soil dry weight basis. In both pathotypes, population densities were higher at shallower depth. In Schach0, this was most pronounced in the entiredepth-treated soil and the deep-treated soil (Table 5); in Schach1, this was a nonsignificant trend within the treatments that was significant for the main factor depth (Table 5). In both pathotypes, Beretta had higher population densities than Sanetta and Pauletta (Table 5).

\section{Discussion}

Populations of $H$. schachtii from below the plow layer $(30 \mathrm{~cm}$ in depth) may reach sugar beet seedlings early in the season when they are most vulnerable to nematode infection. This may partially explain the "surprise observation" of $H$. schachtii damage in presumably $H$. schachtii-free fields when only the plow zone of soil is sampled and examined. This phenomenon was observed on cultivars that were susceptible, resistant, and tolerant to $H$. schachtii. The observation of early root penetration of $H$. schachtii from below plow depths was consistent regardless of cultivar susceptibility or source of the nematode (introduced greenhouse cultures or natural populations suppressed with fosthiazate at predetermined depths). Where entire soil columns contained nematodes, both deep and shallow populations infected plants. Although early reductions of canopies by $H$. schachtii were similar

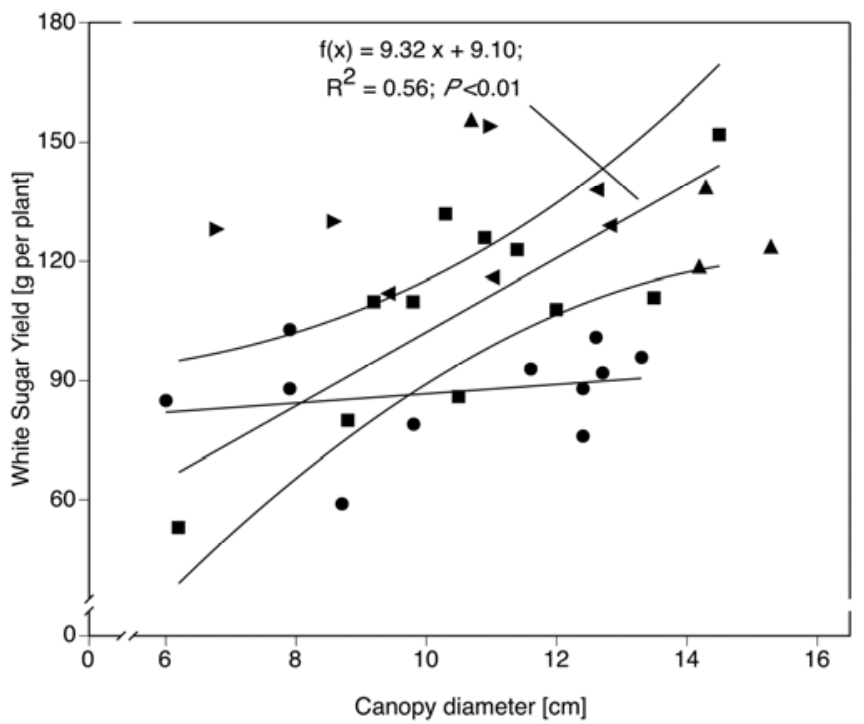

Fig. 2. Relation of white sugar yields at harvest in fall to canopy diameter 5 weeks after planting of sugar beet 'Beretta' (susceptible, $\mathbf{\square})$, 'Sanetta' (resistant, $\mathbf{0}$ ), or 'Pauletta' (tolerant, $\boldsymbol{\nabla}$ = Schach0, infestation; $\boldsymbol{\Delta}=$ Schach0, suppression; $\mathbf{4}=$ Schach1, suppression). Noninoculated controls of the first experiment of Schach0 infestation were omitted from this analysis.

Table 3. Single taproot weights and white sugar yields of 'Beretta', 'Sanetta', and 'Pauletta' in $1 \mathrm{~m}^{2}$ microplots with Heterodera schachtii pathotypes Schach0 or Schach1 treated with fosthiazate at various depth layers ${ }^{\mathrm{y}}$

\begin{tabular}{|c|c|c|c|c|c|c|c|c|c|}
\hline \multicolumn{2}{|c|}{ Nematodes $(\mathrm{cm})^{\mathrm{z}}$} & \multicolumn{4}{|c|}{ Taproot weight (kg) } & \multicolumn{4}{|c|}{ White sugar yield (g) } \\
\hline $0-30$ & $30-60$ & Beretta & Sanetta & Pauletta & Mean & Beretta & Sanetta & Pauletta & Mean \\
\hline \multicolumn{10}{|l|}{ Schach0 } \\
\hline- & - & $0.96 \pm 0.07$ & $0.55 \pm 0.06$ & $0.80 \pm 0.04$ & $0.77 \pm 0.06$ & $152 \pm 12$ & $93 \pm 8$ & $124 \pm 6$ & $123 \pm 9$ \\
\hline+ & + & $0.70 \pm 0.08$ & $0.62 \pm 0.11$ & $1.00 \pm 0.10$ & $0.77 \pm 0.07$ & $110 \pm 13$ & $101 \pm 18$ & $156 \pm 16$ & $122 \pm 11$ \\
\hline+ & - & $0.67 \pm 0.08$ & $0.59 \pm 0.08$ & $0.87 \pm 0.07$ & $0.71 \pm 0.05$ & $108 \pm 13$ & $96 \pm 13$ & $139 \pm 11$ & $114 \pm 8$ \\
\hline - & + & $0.71 \pm 0.11$ & $0.53 \pm 0.06$ & $0.76 \pm 0.04$ & $0.67 \pm 0.05$ & $111 \pm 17$ & $88 \pm 10$ & $119 \pm 7$ & $106 \pm 7$ \\
\hline Mean \pm SE & $\ldots$ & $0.76 \pm 0.05 \mathrm{a}$ & $0.57 \pm 0.04 b$ & $0.86 \pm 0.04 \mathrm{a}$ & $0.73 \pm 0.03$ & $120 \pm 8 \mathrm{a}$ & $94 \pm 6 b$ & $135 \pm 6 a$ & $116 \pm 4$ \\
\hline$P_{\text {Treatment (T) }}$ & $\ldots$ & $\ldots$ & $\ldots$ & $\ldots$ & 0.2800 & $\ldots$ & $\ldots$ & $\ldots$ & 0.3155 \\
\hline$P_{\text {Cultivar (C) }}$ & $\ldots$ & $\ldots$ & $<0.01$ & $\ldots$ & $\ldots$ & $\ldots$ & $<0.01$ & $\begin{array}{l}\cdots \\
\ldots\end{array}$ & $\ldots$ \\
\hline$P_{(\mathrm{T} \times \mathrm{C})}$ & $\ldots$ & $\ldots$ & 0.1621 & $\ldots$ & $\ldots$ & $\ldots$ & 0.1512 & $\ldots$ & $\ldots$ \\
\hline \multicolumn{10}{|l|}{ Schach1 } \\
\hline- & - & $0.81 \pm 0.09$ & $0.60 \pm 0.11$ & $0.89 \pm 0.11$ & $0.77 \pm 0.07 \mathrm{a}$ & $123 \pm 15$ & $92 \pm 18$ & $138 \pm 18$ & $118 \pm 11 \mathrm{a}$ \\
\hline+ & + & $0.53 \pm 0.07$ & $0.36 \pm 0.08$ & $0.73 \pm 0.03$ & $0.54 \pm 0.06 b$ & $80 \pm 11$ & $59 \pm 13$ & $112 \pm 5$ & $84 \pm 9 b$ \\
\hline+ & - & $0.81 \pm 0.11$ & $0.49 \pm 0.11$ & $0.76 \pm 0.08$ & $0.69 \pm 0.07 \mathrm{a}$ & $126 \pm 17$ & $79 \pm 18$ & $116 \pm 12$ & $107 \pm 10 \mathrm{a}$ \\
\hline- & + & $0.56 \pm 0.05$ & $0.47 \pm 0.05$ & $0.86 \pm 0.05$ & $0.63 \pm 0.06 \mathrm{ab}$ & $86 \pm 8$ & $76 \pm 8$ & $129 \pm 7$ & $97 \pm 8 a b$ \\
\hline Mean \pm SE & $\ldots$ & $0.77 \pm 0.05 b$ & $0.48 \pm 0.05 \mathrm{c}$ & $0.81 \pm 0.04 \mathrm{a}$ & $0.65 \pm 0.03$ & $104 \pm 8 b$ & $76 \pm 7 c$ & $124 \pm 6 \mathrm{a}$ & $101 \pm 5$ \\
\hline$P_{\text {Treatment (T) }}$ & $\ldots$ & $\ldots$ & & $\ldots$ & 0.0117 & $\ldots$ & & $\ldots$ & 0.0224 \\
\hline$P_{\text {Cultivar (C) }}$ & $\ldots$ & $\ldots$ & $<0.01$ & $\ldots$ & $\ldots$ & $\ldots$ & $<0.01$ & $\ldots$ & $\ldots$ \\
\hline$P_{(\mathrm{T} \times \mathrm{C})}$ & $\ldots$ & $\ldots$ & 0.5062 & $\ldots$ & $\ldots$ & $\ldots$ & 0.5780 & $\ldots$ & $\ldots$ \\
\hline
\end{tabular}

${ }^{y}$ Means of single plants are reported; numbers are means \pm standard error of the means; data within one column or one row of the same parameter followed by the same letter were not significantly different when log-transformed data $\left(\log _{10}[x+1]\right)$ were tested at $\left.P=0.05\right)$.

${ }^{\mathrm{z}}$ Symbols: $-=$ nematode suppressed with fosthiazate at $7.5 \mathrm{~g} / \mathrm{m}^{2}$ per depth layer or $+=$ nematode present, not chemically treated. 
in the different cultivars, this primary damage was reflected in WSYs only in the susceptible cultivar. The capacity to compensate for early plant damage caused by the nematode may be indicative of tolerance in resistant and tolerant cultivars to infection by $H$. schachtii. This observation suggests that the tolerance was expressed in the development of the sugar beet plants following initial infection, as had been proposed by Gierth and coworkers (4).

The bioassay with radish seedlings, previously used for the demonstration of soil suppressiveness against this nematode (21), was useful for testing efficacy of the nematicide. Chemical nematode suppression was detected at the depth of application of the material but not in the nontreated layers. This had experimental advantages over the use of soil fumigants that move upward, encumbering selectivity of treatments at greater depth (22).

In most exclusion treatments in the experiments reported here, $H$. schachtii colonized layers devoid of nematodes at the beginning of the experiment to levels observed when the nematode had not been reduced. Such recolonization of soil was found for other cyst nematodes (e.g., in potato cyst nematodes; 1 ). The observation of this rapid recolonization was somewhat contrary to the aforementioned Rotylenchulus reniformis, which colonized 1,3-D-treatedlayers quickly if soil was treated only to a depth of $38 \mathrm{~cm}$ but was somewhat slower to colonize soil treated with 1,3-D to a depth of $60 \mathrm{~cm}(22,23)$. Our observation of recolonization during one vegetation period in the $H$. schachtii experiments may be due, in part, to partial resurgence of chemically inactivated nematodes or that different plant-parasitic nematodes prefer certain soil depths. For example, many plant-parasitic nematodes prefer shallow soil layers. Population densities of Meloidogyne arenaria were highest in shallow soil layers in peanut fields (18), and highest population densities of lesion nematodes in dryland farming systems were detected in the upper 0 to $45 \mathrm{~cm}$ of the soil profile (20). Other nematodes prefer greater depths. In California, Longidorus africanus preferred deeper soil layers of 60 to $90 \mathrm{~cm}$ of depth (14).

In a study of the vertical distribution of a lesion nematode under four different crops, the proportions of the population detected at varying depths were similar at different sampling times (15). Such preferences were experimentally simulated when Helicotylenchus pseudorobustus, Pratylenchus penetrans, and $R$. robustus, added to the top of soil columns in plastic tubing, preferred shallower soil layers than Trichodorus spp. and Longidorus spp. (19). In addition to species-specific preferences for soil depth layers, soil physical properties of native soil may also impact the distribution of nematodes in the soil profile, as can an overabundance of clay in the subsurface (8). Agronomic practices also impact this distribution. For example, tillage and crop sequence can have profound effects on the distribution of $R$. reniformis (24), and mixing soils with a

Table 4. Analysis of variance (ANOVA) results of egg population densities in soil collected from 0 - to $30-$ or $30-$ to $60-\mathrm{cm}$ depths from $1-\mathrm{m}^{2}$ in microplots infested with Heterodera schachtii (Schach0) analyzed per 100 $\mathrm{g}$ of field-moist soil, dry soil mass, or per $100 \mathrm{~cm}^{3}$ of soily

\begin{tabular}{lccc}
\hline & \multicolumn{3}{c}{ Eggs per } \\
\cline { 2 - 4 } Parameter $^{\mathbf{z}}$ & $\mathbf{1 0 0}$ g moist & $\mathbf{1 0 0} \mathbf{g} \mathbf{~ d r y}$ & $\mathbf{1 0 0} \mathbf{~ c m}^{\mathbf{2}}$ moist \\
\hline Treatment (T) & 0.5087 & 0.5082 & 0.5130 \\
Cultivar (C) & $<0.01$ & $<0.01$ & $<0.01$ \\
Depth (D) & $<0.01$ & $<0.01$ & $<0.01$ \\
$\mathrm{~T} \times \mathrm{C}$ & 0.2511 & 0.2513 & 0.2515 \\
$\mathrm{C} \times \mathrm{D}$ & 0.7568 & 0.7574 & 0.7576 \\
$\mathrm{~T} \times \mathrm{D}$ & 0.0442 & 0.0432 & 0.0459 \\
$\mathrm{~T} \times \mathrm{C} \times \mathrm{D}$ & 0.1913 & 0.1935 & 0.1943 \\
Block $(\mathrm{B})$ & 0.2869 & 0.2862 & 0.2881 \\
$\mathrm{~B} \times \mathrm{T}$ & $<0.01$ & $<0.01$ & $<0.01$ \\
$\mathrm{~B} \times \mathrm{T} \times \mathrm{C}$ & 0.1404 & 0.1410 & 0.1411 \\
$\mathrm{~B} \times \mathrm{T} \times \mathrm{D}$ & 0.2380 & 0.2489 & 0.2258 \\
\hline
\end{tabular}

${ }^{y}$ Probabilities were indicated for ANOVA of nematode counts per fieldmoist soil (per $100 \mathrm{~g}$ of soil), converted to numbers per soil dry matter (per $100 \mathrm{~g}$ of dry soil), after volumetric conversion (per $100 \mathrm{~cm}^{3}$ of soil).

${ }^{\mathrm{z}}$ Parameters were resorted for simplicity independent of the statistical model; fixed factors were listed first, error terms were grouped below. Probabilities among the calculation basis for the different parameters were similar in Schach1 as well.

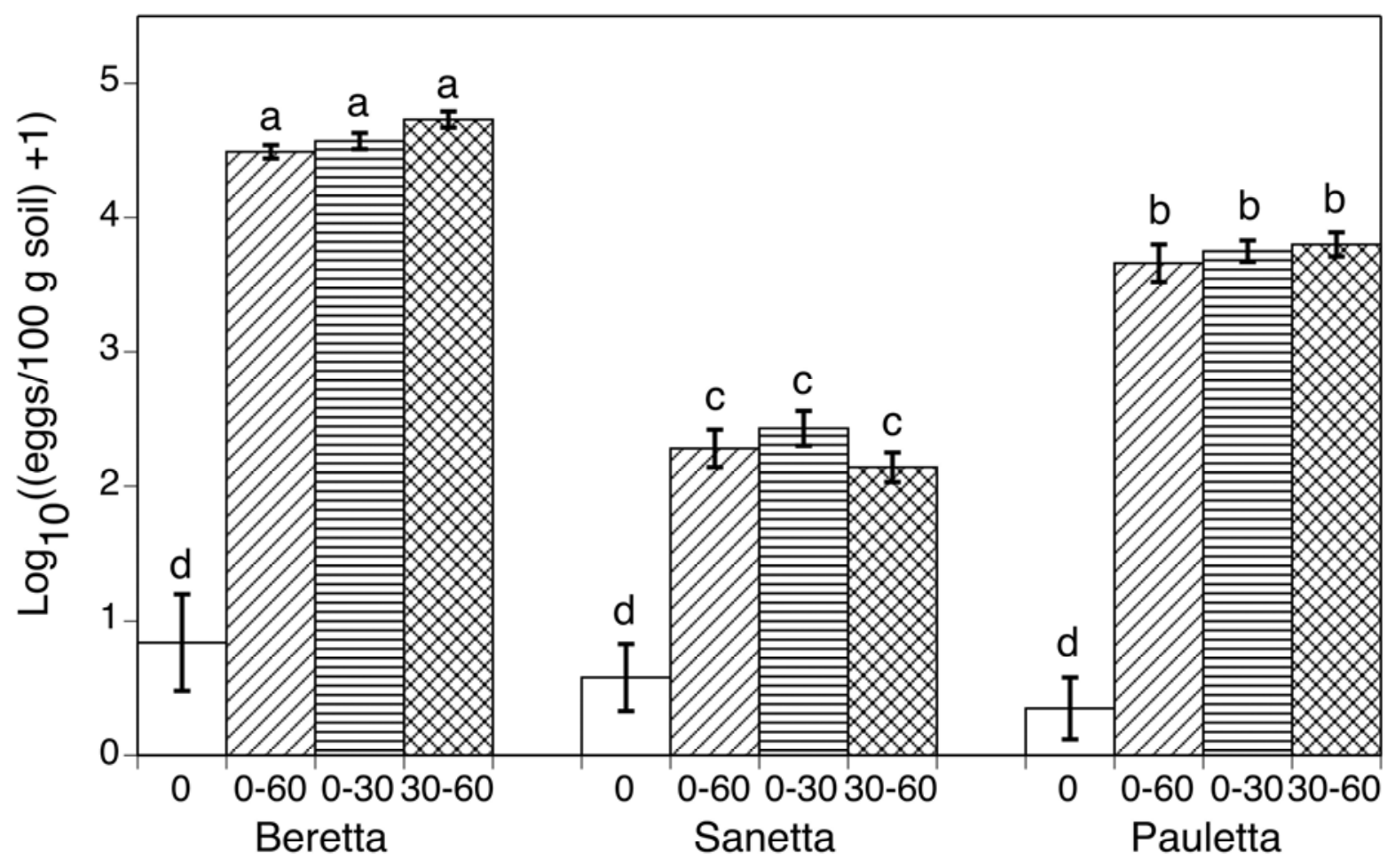

Cultivar and inoculation depth [cm]

Fig. 3. Population densities of Heterodera schachtii at harvest under sugar beet 'Beretta', 'Sanetta', and 'Pauletta' in 30-cm-diameter cores filled with originally steamed soil inoculated with cysts containing the equivalent of 550 eggs per $100 \mathrm{~g}$ of soil at different depths of 0 to 30 or 30 to $60 \mathrm{~cm}$. 
Table 5. $\log _{10}$-transformed data of the final egg population densities of Heterodera schachtii per $100 \mathrm{~g}$ of dry soil at harvest in soil collected from 0-30 or $30-60 \mathrm{~cm}$ after application of fosthiazate at different soil depth layers in $1 \mathrm{~m}^{2}$ microplots infested with Heterodera schachtii ${ }^{\mathrm{y}}$

\begin{tabular}{|c|c|c|c|c|c|c|c|c|c|c|}
\hline \multicolumn{2}{|c|}{ Nematodes $(\mathrm{cm})^{\mathrm{z}}$} & \multirow[b]{2}{*}{ Depth } & \multicolumn{4}{|c|}{ Schach0 } & \multicolumn{4}{|c|}{ Schach1 } \\
\hline 0-30 & $30-60$ & & Beretta & Sanetta & Pauletta & Mean & Beretta & Sanetta & Pauletta & Mean \\
\hline - & - & $0-30$ & $2.2 \pm 0.7$ & $2.4 \pm 0.8$ & $2.1 \pm 0.7$ & $2.2 \pm 0.4 b$ & $3.7 \pm 0.1$ & $3.5 \pm 0.1$ & $3.3 \pm 0.1$ & $3.5 \pm 0.1$ \\
\hline - & - & $30-60$ & $2.1 \pm 0.7$ & $1.8 \pm 0.6$ & $1.7 \pm 0.6$ & $1.9 \pm 0.3 \mathrm{c}$ & $3.4 \pm 0.1$ & $2.9 \pm 0.2$ & $2.8 \pm 0.2$ & $3.0 \pm 0.1$ \\
\hline+ & + & $0-30$ & $3.2 \pm 0.2$ & $2.5 \pm 0.3$ & $2.5 \pm 0.3$ & $2.7 \pm 0.2 \mathrm{a}$ & $3.7 \pm 0.1$ & $3.5 \pm 0.1$ & $3.5 \pm 0.1$ & $3.6 \pm 0.1$ \\
\hline+ & + & $30-60$ & $3.0 \pm 0.1$ & $2.4 \pm 0.4$ & $2.6 \pm<0.1$ & $2.7 \pm 0.1 \mathrm{a}$ & $3.3 \pm 0.1$ & $3.3 \pm 0.1$ & $3.0 \pm 0.2$ & $3.2 \pm 0.1$ \\
\hline+ & - & $0-30$ & $3.3 \pm 0.1$ & $2.5 \pm 0.1$ & $2.9 \pm 0.1$ & $2.9 \pm 0.1 \mathrm{a}$ & $3.7 \pm<0.1$ & $3.4 \pm 0.1$ & $3.4 \pm 0.1$ & $3.5 \pm 0.1$ \\
\hline+ & - & $30-60$ & $2.5 \pm 0.2$ & $2.1 \pm 0.4$ & $2.2 \pm 0.2$ & $2.3 \pm 0.2 b$ & $3.4 \pm 0.1$ & $3.2 \pm 0.2$ & $3.0 \pm 0.1$ & $3.2 \pm 0.1$ \\
\hline - & + & $0-30$ & $3.3 \pm 0.1$ & $2.6 \pm 0.1$ & $2.6 \pm 0.1$ & $2.8 \pm 0.1 \mathrm{a}$ & $3.8 \pm<0.1$ & $3.6 \pm 0.1$ & $3.5 \pm 0.1$ & $3.6 \pm<0.1$ \\
\hline- & + & $30-60$ & $3.0 \pm<0.1$ & $2.6 \pm 0.1$ & $2.6 \pm 0.1$ & $2.7 \pm 0.1 \mathrm{a}$ & $3.4 \pm 0.1$ & $3.4 \pm 0.1$ & $3.2 \pm 0.1$ & $3.3 \pm 0.1$ \\
\hline Cultivar & $\ldots$ & 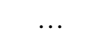 & $2.8 \pm 0.1 \mathrm{a}$ & $2.4 \pm 0.1 \mathrm{~b}$ & $2.4 \pm 0.1 \mathrm{~b}$ & $\ldots$ & $3.5 \pm<0.1 \mathrm{a}$ & $3.3 \pm 0.1 \mathrm{~b}$ & $3.2 \pm 0.1 \mathrm{~b}$ & \\
\hline \multirow[t]{2}{*}{ Depth } & $\ldots$ & $0-30$ & $\ldots$ & $\ldots$ & $\ldots$ & $2.7 \pm 0.1 \mathrm{a}$ & $\ldots$ & $\ldots$ & $\ldots$ & $3.5 \pm<0.1 \mathrm{a}$ \\
\hline & $\ldots$ & $30-60$ & $\ldots$ & $\ldots$ & $\ldots$ & $2.4 \pm 0.1 \mathrm{~b}$ & $\ldots$ & $\ldots$ & $\ldots$ & $3.2 \pm<0.1 b$ \\
\hline$P_{\text {Cultivar (C) }}$ & $\ldots$ & $\ldots$ & $\ldots$ & $<0.01$ & $\ldots$ & $\ldots$ & $\ldots$ & $<0.01$ & $\ldots$ & \\
\hline$P_{\text {Depth (D) }}$ & $\ldots$ & $\ldots$ & $\ldots$ & $\ldots$ & $\ldots$ & $<0.01$ & $\ldots$ & $\ldots$ & $\ldots$ & $<0.01$ \\
\hline$P_{(\mathrm{T} \times \mathrm{D})}$ & $\ldots$ & $\ldots$ & $\ldots$ & $\ldots$ & $\ldots$ & 0.0432 & $\ldots$ & $\ldots$ & $\ldots$ & 0.5938 \\
\hline
\end{tabular}

${ }^{y}$ Numbers are $\log$-transformed data $\left(\log _{10}[x+1]\right)$ means \pm standard error of the means; data within one column or one row of the same parameter followed by the same letter were not significantly different when tested at $P=0.05$.

${ }^{\mathrm{z}}$ Nematodes were expected at certain depths (+) while other layers had been treated with fosthiazate as Nemathorin $10 \mathrm{G}$ at $7.5 \mathrm{~g} / \mathrm{m}^{2}(-)$.

moldboard plow favored reproduction of Heterodera glycines relative to populations in no-till soils (25). Further validation of the concept of damage by deep-occurring populations of $H$. schachtii under varying field conditions is required. Knowledge of the factors responsible for depth preferences, such as moisture requirements of the nematode, would help refine sampling schemes. Similar penetration rates of sugar beet seedlings, whether the cultivars were susceptible or resistant to the cyst nematode, were somewhat expected because similar observations are known from other host plant-parasite interactions. For example, J2 of $M$. incognita initially penetrated roots of resistant soybean more frequently than those of susceptible plants (6); the expression of incompatibility followed after this initial, relatively indiscriminating penetration. In the current study, nematode reproduction was a function of the host suitability more than a result of the infestation layer. This was expected because such observations were made with other nematodes as well (e.g., $R$. reniformis; 22,23).

The fact that plant canopy diameter 5 weeks after planting predicted WSYs in the susceptible Beretta was a reminder of the importance of protection of a susceptible cultivar against the nematode during early plant growth. The lack of such a relationship in the resistant and tolerant cultivars was possibly indicative for tolerance mechanisms expressed in the cultivars after plant establishment. This has implications when testing for tolerance (i.e., short-term assays to detect plant tolerance to $H$. schachtii may be inappropriate).

\section{Acknowledgments}

Provision of the fosthiazate and sugar beet seed by the respective companies is acknowledged. Experimental application of fosthiazate on sugar beet was approved by the State Plant Protection Service. Grant support by the Association of the German Sugar Industry ("Verein der Deutschen Zuckerindustrie") is greatly appreciated. I thank M. Daub and the sugar beet testing laboratory at Jülich for conducting the beet content evaluations; J. Banyari, P. Dahlin, I. Dörries, H. Grosse-Lengerich, F. Lange, and A. Windt for excellent technical assistance; and L. Dunkle and A. Nyczepir for discussion and suggestions.

\section{Literature Cited}

1. Been, T. H., and Schomaker, C. H. 1999. Fumigation of marine clay soils infested with Globodera pallida and G. rostochiensis using 1,3-dichloropropene and additional top soil treatments. Nematology 1:3-14.

2. Byrd, D. W., Kirkpatrick, T., Jr., and Barker, K. R. 1983. An improved technique for clearing and staining plant tissues for detection of nematodes. J. Nematol. 15:142-143.

3. Cooke, D. 1991. Europe goes green to control beet cyst nematode. Br. Sugar Beet Rev. 59:44-47.

4. Gierth, K., Hallmann, J., Schlang, J., Muller, J., and Sikora, R. A. 2004. Plant tolerance for managing plant-parasitic nematodes. Bull. OILB/SROP 27:67-73.

5. Hallmann, J., Daub, M., Grundler, F., and Westphal, A. 2009. 150 Jahre Heterodera schachtii: Ein Überblick der frühen Arbeiten. [150 years Heterodera schachtii: A historical review of the early work.] J. Cult. Plants 61:429-439.

6. Herman, M., Hussey, R. S., and Boerma, H. R. 1991. Penetration and devel- opment of Meloidogyne incognita on roots of resistant soybean genotypes. J. Nematol. 23:155-161.

7. Mai, W., and Abawi, G. 1979. The sugar beet cyst nematode, an important pest of red beets and cabbage. Cornell Univ. Coop. Ext. Fact Sheet 750.10.

8. McSorley, R., and Frederick, J. J. 2002. Effect of subsurface clay on nematode communities in a sandy soil. Appl. Soil Ecol. 19:1-11.

9. Meier, U., Bachmann, E., Buhtz, H., Hack, H., Klose, R., Märländer, B., and Weber, E. 1993. Phenological growth stages of beta beets (Beta vulgaris L. spp.). Nachrichtenbl. Deut. Pflanzenschutzd. 45:37-41.

10. Müller, J. 1980. Ein verbessertes Extraktionsverfahren für Heterodera schachtii. [An improved method for the extraction of Heterodera schachtii.] Nachrichtenbl. Deut. Pflanzenschutzd. 32:21-24.

11. Müller, J. 1998. New pathotypes of the beet cyst nematode (Heterodera schachtii) differentiated on alien genes for resistance in beet (Beta vulgaris). Fundam. Appl. Nematol. 21:519-526.

12. Müller, J. 1998. Resistance and tolerance to beet cyst nematodes (Heterodera schachtii) in sugar beet cultivars. Zuckerindustrie 9:688-693.

13. Müller, J. 1999. The economic importance of Heterodera schachtii in Europe. Helminthologia 36:205-213.

14. Ploeg, A. 1998. Horizontal and vertical distribution of Longidorus africanus in a bermudagrass field in the Imperial Valley, California. J. Nematol. 30:592-598.

15. Pudasaini, M. P., Schomaker, C. H., Been, T. H., and Moens, M. 2006. Vertical distribution of the plant-parasitic nematode, Pratylenchus penetrans, under four field crops. Phytopathology 96:226-233.

16. Robinson, A. F., Akridge, R., Bradford, J. M., Cook, C. G., Gazaway, W. S., Kirkpatrick, T. L., Lawrence, G. W., Lee, G., McGawley, E. C., Overstreet, C., Padgett, B., Rodriguez-Kabana, R., Westphal, A., and Young, L. D. 2005. Vertical distribution of Rotylenchulus reniformis in cotton fields. J. Nematol. 37:265-271.

17. Robinson, A. F., Cook, C. G., Westphal, A., and Bradford, J. M. 2005. Rotylenchulus reniformis below plow depth suppresses cotton yield and root growth. J. Nematol. 37:285-291.

18. Rodríguez-Kábana, R., and Robertson, D. G. 1987. Vertical distribution of Meloidogyne arenaria juvenile populations in peanut fields. Nematropica 17:199-208.

19. Rössner, J. 1972. Vertikalverteilung wandernder Wurzelnematoden im Boden in Abhängigkeit von Wassergehalt und Durchwurzelung. [Vertical distribution of migratory root nematodes in soil in relation to water content and extent of root system.] Nematologica 18:360-372.

20. Smiley, R. W., Sheedy, J. G., and Easley, S. A. 2008. Vertical distribution of Pratylenchus spp. in silt loam soil and Pacific Northwest dryland crops. Plant Dis. 92:1662-1668.

21. Westphal, A., and Becker, J. O. 2001. Impact of soil suppressiveness on various population densities of Heterodera schachtii. Ann. Appl. Biol. 138:371-376.

22. Westphal, A., Robinson, A.F., Scott, A. W., Jr., and Santini, J. B. 2004 Depth distribution of Rotylenchulus reniformis under crops of different host status and after fumigation. Nematology 6:97-107.

23. Westphal, A., and Scott, A. W. 2005. Implementation of soybean in cotton cropping sequences for management of Rotylenchulus reniformis in South Texas. Crop Sci. 45:233-239.

24. Westphal, A., and Smart, J. 2003. Depth distribution of Rotylenchulus reniformis under different tillage and crop sequence systems. Phytopathology 93:1182-1189.

25. Westphal, A., Xing, L. J., Pillsbury, R., and Vyn, T. J. 2009. Effects of tillage on population densities of Heterodera glycines. Field Crops Res. $113: 218-226$ 